\title{
Systematic Review: Laparoscopic Gastrectomy in Locally Advanced Gastric Cancer: Is It Viable?
}

\author{
Henrique BeletableFonseca ${ }^{1}$, Luiza Ohasi de Figueiredo ${ }^{2}$, Jo o Paulo Silva Vieira ${ }^{1}$, Sillas Mourão Pinto ${ }^{1}$, Diego \\ Paim Carvalho Garcia ${ }^{3}$, Luiz Ronaldo Alberti** and Thiago de Almeida Furtado ${ }^{5}$
}

${ }^{1}$ Department of Surgery, Hospital Universitário Ciências Médicas de Minas HUCM-MG, Brazil

${ }^{2}$ Department of Surgery, Hospital Felício Rocho, Belo Horizonte, Brazil

${ }^{3}$ Department of Surgery, Instituto de Ensino e Pesquisa da Santa Casa, Belo Horizonte, Brazil

${ }^{4}$ Department of Surgery, FMUFMG and Instituto de Ensino e Pesquisa da Santa Casa, Brazil

${ }^{5}$ Department of Surgery, Hospital Universitário Ciências Médicas de Minas Gerais (HUCM-MG) and Hospital FelícíoRocho, Brazil

Submission: April 06, 2017; Published: May 03, 2017

"Corresponding author: Luiz Ronaldo Alberti, Associate Professor, General Surgeon, Department of Surgery, Instituto de Ensino e Pesquisa Santa Casa BH, R Domingos Viêira, 590-Santa Efigênia, Belo Horizonte-MG, 30150-240, Brazil, Email: luizronaldo@yahoo.com.br

\begin{abstract}
Introduction: Gastric cancer is one of the most important pathologies of the digestive tract, representing the fifth most common cause of cancer, with the adenocarcinoma being the main histological type. Standard approach for the treatment of the gastric tumors is surgical resection, performed laparotomically or laparoscopically. In the past years, the minimally invasive procedure had a significant improvement making the laparoscopy progressively viable, mostly for the initial early staged tumors.
\end{abstract}

Objective: This systematic review aims to determine the efficiency of the laparoscopic approach on the treatment of locally advanced gastric cancer.

Methodology: The present study is a systematic review of eight systematic reviews published in the past 5 years.

Discussion: According to the publications analyzed, the only parameter in which conventional gastrectomy was superior to laparoscopic gastrectomy was surgical length. Many authors justify this difference by saying that the minimally invasive procedure has a higher complexity of performance of the gastrointestinal transit reconstruction, as well as the more complex lymphadenectomy. It is also take into account the preparing of materials and laparoscopic instruments, the decrease of tactical sensation and the different levels of expertise of the surgeons performing the procedure. Bleeding, length of hospitalization, pain and complication rates was all smaller in the laparoscopic approach.

Conclusion: Based on all the analyzed reviews, laparoscopic gastrectomy proved to be as viable as the conventional technique when opted for approach of a gastric adenocarcinoma, presenting, in the majority of parameters, better results than of open surgery. Nevertheless, some considerations are still necessary.

Keywords: Gastric cancer; Laparoscopy; Systematic review; Laparotomy; Locally advanced

\section{Introduction}

The gastric cancer is one of the most important pathologies of the digestive tract, representing the fifth most common cause of cancer, with the adenocarcinoma being the main histological type [1]. It is staged according to the 7th edition of the American Joint Committee on Cancer (AJCC) staging manual for gastric cancer, in which it was determined that the early stage (T1) is when the tumor remains confined to the sub mucous tissue, with or without lymph node metastasis, and the advanced stage being the one with invasion of submucous tissues [2]. According to the Brazilian Consensus of Gastric Cancer, issued in 2013 and following AJCC staging parameters, the locally invasive gastric cancer is the one classified by the TNM system as T4N0$2 \mathrm{M} 0$, meaning that there is invasion of visceral peritoneum (serosa), with lymph node metastasis up to 6 regional lymph nodes, without metastatic disease (M0) $[3,4]$. Being the abovementioned parameters the ones used to assess the level of invasion of gastric tumors in this study. 
According AJCC's 7th edition, the survival rates observed above 5 years, according to each stage, are: T1-98\%; T2-75,8\%; T3-48,9\%; T4-25\% [4]. Due to this statistics, it is advisable thotrat the patient as soon as possible, having a higher possibility of live free of disease, and being less surgically aggressive in order to improve post operative status.

The standard approach for the treatment of the gastric tumors is surgical resection, performed laparotomically or laparoscopically. The laparotomic gastrectomy - also called open or conventional gastrectomy (CG)-is made by a midline incision or by the Chevron incision (also known as bilateral subcostal incision or double Kocher incision). For the laparoscopic gastrectomy (LG), two different approaches can be used, depending on the option for the reconstruction of the intestinal transit. The laparoscopically assisted gastrectomy (LAG) uses a $5 \mathrm{~cm}$ epigastric mini-laparotomy (besides the laparoscopic trocar placement) in order to perform the anastomosis outside de abdominal cavity. In other hand, the totally laparoscopic technique for gastrectomy (TLG) uses only the trocar placement as approach due to the intrabdominal anastomosis $[1,4]$.

The first reported laparoscopic surgery for gastric cancer was made in 1994 by Kitano, who performed a LAG with lymphadenectomy for an early staged gastric tumor [5].

In the past years, the minimally invasive procedure had a significant improvement making the laparoscopy progressively viable, mostly for the initial early staged tumors. The efficiency and safety of the laparoscopic approach in tumors with higher staging, such as the locally invasive, is under discussion and has not been established yet.

Therefore, this systematic review aims to determine the efficiency of the laparoscopic approach on the treatment of locally advanced gastric cancer.

\section{Methodology}

The present study is a systematic review of eight systematic reviews published in the past 5 years. The databases PubMED,
SciELO and LILACS were used for the research of the following keywords: "laparoscopic gastrectomy locally gastric cancer"; "laparoscopic gastrectomy"; "open gastrectomy for advanced gastric cancer", resulting in 4183 studies found (Figure 1). Inclusion criteria determined that only systematic reviews and clinical trials, published between 2011 and 2016 and reporting adenocarcinoma as histological finding for gastric cancer were used.

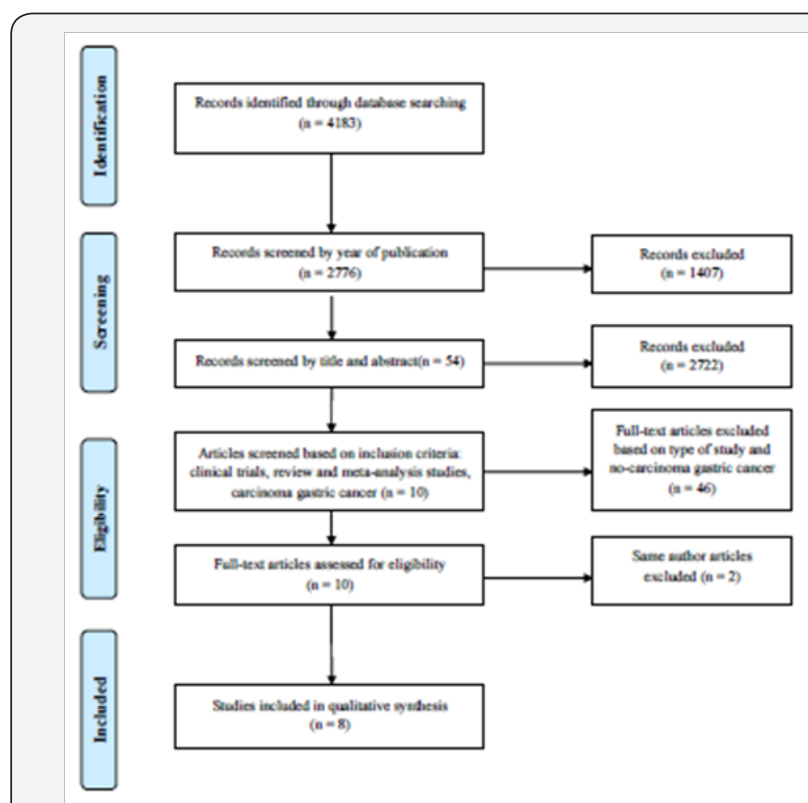

(Based on flowchart from PRISMA 20096)

Figure 1: Flowchart of Systematic Review Methodology.

Exclusion criteria eliminated cohort, observational studies, case-control and case reports, published more than five years from date of research and that reported other histological types of gastric cancer besides adenocarcinoma. For articles published by the same author, only the most recent were considered. The research, after the application of the above-mentioned parameters resulted in eight articles (Table 1).

Table 1: Analyzedpublications

\begin{tabular}{|c|c|c|c|c|}
\hline Authors & Publications & Number of Cases & $\begin{array}{l}\text { Conventional } \\
\text { Gastrectomy }\end{array}$ & $\begin{array}{c}\text { Laparoscopic } \\
\text { Gastretomy Cancer } \\
\text { Satging }\end{array}$ \\
\hline Chen et al. [7] & 2014 & 1532 & 811 & All satges \\
\hline Huang et al. [8] & 2014 & 1904 & 982 & Satging not mentioned \\
\hline Choi et al. [9] & 2013 & Not mentioned & Not mentioned & Satging not mentioned \\
\hline Ding et al.[10] & 2012 & 1065 & 510 & All stages \\
\hline Haverkamp et al. [11] & 2012 & 698 & 314 & All stages \\
\hline Wei et al. [12] & 2011 & 1039 & 495 & Satging not mentioned \\
\hline $\begin{array}{c}\text { Martinez-Ramos et al. } \\
\text { [13] }\end{array}$ & 2011 & 452 & 278 & Satging not mentioned \\
\hline Cai et al. [14] & 2011 & 123 & 61 & All stages \\
\hline
\end{tabular}


Results

A study performed by Chen et al. [7] compared the laparoscopic and laparotomic approaches. It evaluated articles published until 2014, finding 14 suitable publications (1 randomized clinical trial and 13 observational studies). It covered 1532 patients from nine different regions (Italy, Belgium, France, USA, Chile, South Korea, Japan, Taiwan and Hong Kong), being 721 submitted to laparoscopy and 811 to laparotomy. By the end of the study, the conclusion was that the bleeding and need for transfusion, necessity of painkillers, recovery of gastrointestinal functions, dietary restart and the number of complications (cardiorespiratory, metabolic, pulmonary embolism/deep venous embolism and non-surgical infections) were smaller regarding the patients submitted to the laparoscopic approach. Also, the duration of hospitalizations proved to be, in average, 3,75 days smaller for those patients. Nevertheless, the conventional - laparotomic - approach presents shorter surgical time. Parameters such as: number of resected lymph nodes, distal and proximal margins, taxes of surgical related complications (regarding anastomosis, intrabdominal collections, bleeding, surgical wound and delayed gastric emptying, among others), mortality and morbidity taxes did not present a different result comparing both approaches. The recurrence of tumors was seen in $22,7 \%$ of the laparoscopic gastrectomies and in $21,9 \%$ of the laparotomic, not representing a considerable statistical difference according to the results of the study.

Huan et al. [8] selected 11 articles for their systematic revision, published between January 2000 and September 2013. A total of 1904 gastrectomies with D2 lymphadenectomy were analyzed, 982 of them being performed via laparoscopy and 922 via laparotomy. A statistical equivalence was seen regarding survival rates, bleeding and complications. Surgical time was shorter for the conventional approach and infectious complications were seen in smaller proportion on patients submitted to laparoscopy.

The systematic review published by Yoon Young Choi et al. [9] analyzed 10 other studies (9 cohort and one randomized clinical trial). The authors concluded that there was no statistical difference when comparing average survival rate or free of disease survival rate for both laparoscopic and laparotomic approaches.

Ding et al. [10] analyzed eight retrospective casecontrol studies, with a total of 1065 gastrectomies with D2 lymphadenectomy, 510 laparoscopic and 555 conventional ones. Regarding the decrease of use of painkillers, they concluded that the minimally invasive procedure had an advantage compared to the conventional surgery. However, the studies were not capable to show whether the lymphadenectomy performed during the laparosocopic gastrectomy is adequate or its long term prognostic. Another disadvantage seen, was the increase in the surgical time and the requirement of more experienced surgeons and more developed technology. As advantages, the laparoscopy showed less complication rates and fewer hospitalization days.

Haverkamp's [11] review included eight randomized clinical trials. Compared to the conventional approach, the laparoscopy is associated with a considerable reduction of post-surgical complications, bleeding and time of hospitalization. In other hand, the study reinforces the need of better studies to evaluate the mortality rates, resection margins and number of resected lymph nodes.

The meta-analysis written by Wei [12] evaluated ten studies published between the years of 2001 to 2010, being classified as one clinical trial and nine case-controls. It comprised 1039 patients, 495 submitted to gastrectomy via laparoscopy and 544 via laparotomy. The number of resected lymph nodes, the anastomotic leak and the survival rates in 5 years had no major differences between the two methods. They concluded yet that the bleeding, need of painkillers, reestablishment of gastrointestinal function, length of hospitalization and surgical wound infection were lower in patients submitted to LG. Still, the average surgical time of the conventional approach was around 57,14 minutes shorter.

The Spanish meta-analysis of Martínez-Ramos [13] analyzed seven clinical trials (one of them randomized). The total of assessed patients were 452 , with 174 laparoscopic gastrectomies performed. The bleeding volume during the laparoscopic approach was $122 \mathrm{~mL}$ smaller in average and the hospitalization took around 6 days less when compared to open gastrectomy. Nevertheless, the CG took $44 \mathrm{~min}$ less to be performed, in general. The number of resected lymph nodes was statistically similar in both approaches. In the same way, the survival rate in 5 years showed not to differ in both groups.

In 2011, Cai et al. [14] published a randomized clinical trial comparing LG and CG in patients diagnosed with advanced staged gastric cancer. Between March 2009 and December 2010, 123 patients were evaluated. Sixty two of them were submitted to LG and 62 to CG. According to the authors, the first approach shower smaller morbidity and mortality rates, less complications and lesser hospitalization time. However, CG still had a faster length of performance. The study showed no statistical differences regarding survival rates.

\section{Discussion}

According to the publications analyzed, the only parameter in which CG was superior to LG was regarding surgical length. Many authors justify this difference by saying that the minimally invasive procedure has a higher complexity of performance of the gastrointestinal transit reconstruction, as well as the more complex lymphadenectomy. It is also take into account the preparing of materials and laparoscopic instruments, the decrease of tactical sensation and the different levels of expertise of the surgeons performing the procedure [7-14]. 
The incidence of bleeding and need of transfusion were smaller when the laparoscopic approach was utilized. That occurs due to better visualization of vascularization and better instruments available $[7,11,13]$. Only one of the mentioned articles concluded that the bleeding incidence in both procedures was similar [9].

There was a decrease on the need of use of painkillers and lower complication rates in the groups submitted to gastrectomy via laparoscopy, that fact is justified by the minimally invasive type of approach [7-11,14].

The early reestablishment of gastrointestinal function, evaluated by the elimination of flatulence by the patients $[7,12]$, associated with an early progression of diet7 occurs due to less mobilization of the intrabdominal cavity, with formation of looser adhesions, leading to a reduced ileus.

The results of reduced hospitalization time seen in patients submitted to laparoscopic gastrectomy [7,11-14], it may occur due to minimal manipulation of the intestines leading to early reestablishment of gastrointestinal function, reductions of inflammatory reaction and fast return to daily activities.

Regarding the number of resected lymph nodes and of tumoral recurrence and survival rates, both techniques showed no statistical differences [7-9,12-14]. This conclusion is only possible due to comparisons between experienced surgeons, being this level of expertise acquired approximately after 40 performed surgeries6. One of the studies concludes that further investigation is necessary to define which approach is most advantageous on the matter of lymph node resection. Two articles also mention the need for more studies to obtain a certain level of oncological safety for the extrapolation of the recurrence and survival rates obtained $[7,13]$.

Two of the parameters analyzed showed no consensus between two revisions: tumor resection margin and morbidity and mortality rates. As for the resection margins, a study [7] did not find a statistically significant difference in this regard when compared the two gastrectomy techniques. Another article says more studies may be needed to better define the resection margin standards [11].

As for the morbidity and mortality rates, no definite conclusion could be made. One of the revisions showed no statistical difference in the criteria for the two surgical approaches [7]; another claims the laparoscopic technique to be the one with lower morbidity and mortality [14]; and still, another review infers the need for further studies to be performed to determine the rates for each type of approach [15].

In addition to the revisions mentioned above, there are yet two ongoing randomized clinical trials. The KLASS-02 study [15] covers 1050 patients equally divided (525) between the groups submitted to laparoscopic and conventional gastrectomy. Participants with early staged gastric cancer, with muscularispropria invasion, but not adjacent organs invaded (T2 to T4), with no lymph node or limited to perigastric lymph nodes metastasis were selected for this study. The authors aim to demonstrate that there is no inferiority of the laparoscopic approach in the free of disease rate in 3 years.

The second ongoing study is the LOGIC-trial [16]. In this trial, 210 participants with surgically resectable gastric cancer (T1-4b, N0-3b, M0) are divided equally between the two groups (laparoscopy X conventional gastrectomy). It aims to demonstrate that laparoscopic gastrectomy has the same benefits to patients provided by the conventional technique, but with less blood loss during the surgery, lower complication rates and shorter hospitalization period.

Finally, a systematic review with meta-analysis performed by Zhang [4] compared two techniques in laparoscopic gastric cancer approach: assisted laparoscopic gastrectomy and the totally laparoscopic technique. The study included 12 observational studies with 2255 patients (1228 submitted to ALG and 1027 submitted to the TLG). They concluded that bleeding and hospitalization period were lower in the fully laparoscopic technique. The rest of the parameters analyzed, such as: time of surgery, the number of lymph nodes resected, the need for painkillers, time for elimination of flatulence, dietary reintroduction, morbidity and complication rates with anastomoses showed no significant differences between the two techniques. In this study, the authors did not mention the cancer staging of the patients operated.

\section{Conclusion and Final Considerations}

Based on all the analyzed reviews, the laparoscopic gastrectomy proved to be as viable as the conventional technique when opted for approach of a gastric adenocarcinoma, presenting, in the majority of parameters, better results than those of open surgery. It must be expected that even the laparoscopic technique is bound to further development in the future, being performed by single incision even $[17,18]$. Nevertheless, some considerations are still necessary.

Most studies do not have a clear definition of locally advanced cancer, having the majority of them not mentioned the stages of gastric cancer of the patients operated, causing a great impairment for definitive conclusion about the viability of the laparoscopic technique for the disease, despite the positive results. Furthermore, due to the fact that each systematic review assessed a limited number of studies (with an exception of the randomized clinical trials), they present lower levels of evidence and the results might not truly match with the reality. Factors such as the lack randomization of participants, unexperienced surgeons, small samples, large heterogeneity between groups and short postoperative follow-up have to be taken into consideration. 
Therefore, it is recommended to wait for the conclusions of the ongoing clinical trials. Moreover, even stimulate new studies using AJCC's gastric cancer staging, in order to achieve greater impact for the medical and scientific community.

\section{References}

1. Gurusamy KS (2014) Laparoscopic versus open gastrectomy for gastric cancer. Surgery 155(1):154-64.

2. Zilberstein B, Malheiros C, Lourenço LG, Kassab P, Jacob CE, et al. (2013) brasileiro sobre câncer gástrico: diretrizes para o câncer gástrico no Brasil. ArqBrasCirDig 26(1): 2-6.

3. Washington $\mathrm{K}(2010) 7^{\text {th }}$ edition of the AJCC cancer staging manual: stomach. Ann SurgOncol 17(12): 3077-3079.

4. Zhang YX, Wu YJ, Lu GW, Xia MM (2015) Systematic review and metaanalysis of totally laparoscopic versus laparoscopic assisted distal gastrectomy for gastric cancer. World J Surg Oncol 13: 116.

5. Kitano S, Isso Y, Moriyama M, Sugimachi K (1994) Laparoscopy-assisted Billroth I gastrectomy. SurgLaparosc Endosc 4(2): 146-148.

6. Moher D, Liberati A, Tetzlaff J, Altman DG, PRISMA Group (2010) Preferred Reporting Items for Systematic Reviews and Meta-Analyses: The PRISMA Statement. Int J Surg 8(5): 336-341.

7. Chen K, Pan Y, Cai JQ, Xu XW, Wu D, et al. (2014) Totally laparoscopic gastrectomy for gastric cancer: A systematic review and meta-analysis of outcomes compared with open surgery. World J Gastroenterol 20(42): 15867-1578.

8. Huang YL, Lin HG, Yang JW, Jiang FQ Zhang T, et al. (2014) Laparoscopyassisted versus open gastrectomy with D2 lymph node dissection for advanced gastric cancer: a meta-analysis. Int J ClinExp Med 7(6): 14901499.

9. Choi YY, Bae JM, An JY, Hyung WJ, Noh SH (2013) Laparoscopic gastrectomy for advanced gastric cancer: are the long-term results comparable with conventional open gastrectomy? A systematic review and meta-analysis. J Surg Oncol 108(8): 550-556.

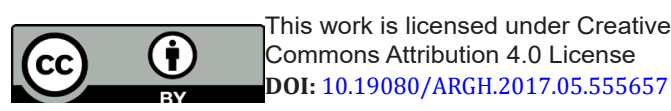

10. Ding J, Liao GQ Liu HL, Liu S, Tang J (2012) Meta-analysis of laparoscopyassisted distal gastrectomy with D2 lymph node dissection for gastric cancer. J SurgOncol 105(3): 297-303.

11. Haverkamp L, Weijs TJ, van der Sluis PC, van der Tweel I, Ruurda JP, et al. (2013) Laparoscopic total gastrectomy versus open total gastrectomy for cancer: a systematic review and meta-analysis. SurgEndosc 27(5): 1509-20.

12. Wei HB, Wei B, Qi CL, Chen TF, Huang Y, et al. (2011) Laparoscopic versus open gastrectomy with D2 lymph node dissection for gastric cancer: a meta-analysis. Surg Laparosc Endosc Percutan Tech 21(6): 383-390.

13. Martinez-Ramos D, Miralles-Tena JM, Cuesta MA, Escrig-Sos J, Van der Peet D, et al. (2011) Laparoscopy versus open surgery for advanced and resectable gastric cancer: a meta-analysis. Rev EspEnferm Dig 103(3): 133-141.

14. Cai J, Wei D, Gao CF, Zhang CS, Zhang H, et al. (2011) A Prospective Randomized Study Comparing Open versus Laparoscopy-Assisted D2 Radical Gastrectomy in Advanced Gastric Cancer. Dig Surg 28(5-6): 331-337.

15. Hur H, Lee HY, Lee HJ, Kim MC, Hyung WJ, et al. (2015) Efficacy of laparoscopic subtotal gastrectomy with D2 lymphadenectomy for locally advanced gastric cancer: the protocol of the KLASS-02 multicenter randomized controlled clinical trial. BMC Cancer 15: 355.

16. Haverkamp L, Brenkman HJ, Seesing MF, Gisbertz SS, van Berge Henegouwen MI, et al. (2015) LOGICA study group. Laparoscopic versus open gastrectomy for gastric cancer, a multicenter prospectively randomized controlled trial (LOGICA-trial). BMC Cancer 15: 556.

17. Park DJ, Lee JH, Ahn SH, Eng AK, Kim HH (2012) Single-port laparoscopic distal gastrectomy with $D 1+\beta$ lymph node dissection for gastric cancers: report of 2 cases. Surg Laparosc Endosc Percutan Tech 22(4): e214-216.

18. Ahn SH, Son SY, Jung DH, Park do J, Kim HH (2014) Pure single-port laparoscopic distal gastrectomy for early gastric cancer: comparative study with multi-port laparoscopic distal gastrectomy. J Am Coll Surg 219(5): 933-943.

\section{Your next submission with JuniperPublishers will reach you the below assets}

- Quality Editorial service

- Swift Peer Review

- Reprints availability

- E-prints Service

- Manuscript Podcast for convenient understanding

- Global attainment for your research

- Manuscript accessibility in different formats

( Pdf, E-pub, Full Text, audio)

- Unceasing customer service

Track the below URL for one-step submission https://juniperpublishers.com/online-submission.php 